http://www.jfas.info

\title{
AN INTELLIGENT LIGHTING CONTROL SYSTEM (ILCS) USING LABVIEW
}

S. B. Mohamed ${ }^{1, *}$, M. Minhat ${ }^{2}$, M. S. Kasim², M. H. M. Adam², M. A. Sulaiman ${ }^{2}$ and Z. I. $\operatorname{Rizman}^{3}$

${ }^{1}$ East Coast Environmental Research Institute, Universiti Sultan Zainal Abidin, 21300 Terengganu, Malaysia

${ }^{2}$ Faculty of Manufacturing Engineering, Universiti Teknikal Melaka Malaysia, 76100 Melaka, Malaysia

${ }^{3}$ Faculty of Electrical Engineering, Universiti Teknologi MARA, 23000 Dungun, Terengganu, Malaysia

Published online: 08 August 2017

\begin{abstract}
An Intelligent Lighting Control System (ILCS) was proposed and designed by considering ergonomic setting and energy efficiency. The integration of CompactRIO as a main hardware and National Instrument Laboratory Virtual Instrument Engineering Workbench (NI LabVIEW) 2012 as a platform to design an interactive Graphical User Interface (GUI) as well as integrating components within the system. The proportional-integral-derivative (PID) controller programmed in NI LabVIEW provides autonomous dimmer control and adjustment of the light-emitting diode (LED) lamp with respect to present Lux value. Performance tests conducted shows the developed system capable of controlling the luminosity of the LED lamp based on the luminance set point. Moreover, the result also showed the average power saving of up to $33 \%$ compared to normal use. However, several modifications and improvements are desired before the system could be applied in actual environment.
\end{abstract}

Keywords: LabVIEW; data logging; energy saving; light intensity.

Author Correspondence, e-mail: saifulbahri@unisza.edu.my

doi: http://dx.doi.org/10.4314/jfas.v9i2s.38 


\section{INTRODUCTION}

Nowadays, many efforts in emphasizing for green environment and energy saving which becoming more prominent. Electrical appliances, automobiles, airplanes and security system demand the ability of these systems to adapt according to the current situation and capable of autonomously analyzes data and responds to the preset requirement [1]. Although various systems in the real world are becoming more intelligent, only a few of these intelligent applications have been applied to lighting systems which are necessary and important part of human life [2]. Energy saving and Intelligent Lighting Control System (ILCS) are the important trends of lighting technology scenario. Designing of the ILCS that is automatically capable of providing an appropriate illuminance to an arbitrary location as well as allowing other lighting to compensate illuminates in response to the failure of a lighting device has proved to be a challenging task. Moreover, the system should be able to flexibly react and respond when lighting or illuminance sensors are added or when room partitions are changed. The lighting control strategy has an important effect on people's perception and it should be the trend for future ILCS, which combining the human needs with lighting control technology [3]. The increased adoption of light emitting diodes (LEDs) in luminaries, lighting systems can be flexibly and dynamically controlled for illumination rendering [4]. Illumination effects may be designed for better visual comfort and energy-efficiency. The breadth of lighting applications is further enhanced due to the greater amount of sensing, communication, computation and control functions embedded across the lighting system even up to the luminaire-level. An ILCS can save energy, money and significantly contribute to a comfortable working environment making it an indispensable component in modern commercial buildings [5]. Moreover, the ILCS can reduce energy consumption as automatically controlling the intensity of illumination through situation awareness such as awareness of user movement or brightness of the surroundings [6].

Moreover, in the related of previous studies have described about the significant findings and importance role of this research. For examples, in [7] has designed a smart house control using LabVIEW, research by [8] have implemented an energy efficient smart home based on wireless sensor network using LabVIEW, in [9] explained about a RS-485/MODBUS based 
intelligent building automation system using LabVIEW, research by [10] presents about an energy efficiency of alternative lighting control systems, in [11] proposed a design of intelligent residential lighting control system based on Zigbee wireless sensor network and fuzzy controller, research by [12] shows a smart home energy management system for monitoring and scheduling of home appliances using Zigbee, in [13] illustrated a Labview-based fuzzy controller design of a lighting control system, research by [14] demonstrated a hybrid system for daylight responsive lighting control, in [15] Indicated an emergency lighting monitoring system using LonWorks, research by [16] applied a lighting control system in buildings based on fuzzy logic, in [17] has developed a fuzzy controller design of lighting control system by using VI package, research by [18] used a ZigBee wireless technique for an intelligent house lighting control system, in [19] measured an advanced control system for reducing the energy consumption of public street lighting systems, research by [20] analyzed High-power-factor electronic ballast with intelligent energy-saving control for ultraviolet drinking-water treatment systems, etc.

Therefore, the main objective of the research project is to design an ILCS that is capable of controlling and responding an appropriate amount of illumination within simulated lighting environment which in turn providing reduction of energy consumption compared to a normal usage. The ILCS module consists of a presence sensor or motion sensor, light sensor and a main controller. The light sensor can measure luminance values at all calculation points in its associated local zone. The presence sensor detects the presence of occupants within its local zone. The local controller will collect the information from the presence sensor and light sensor during the control procedure. The local controller will match the luminous of LED lamp to a user specified set point by using the PID close loop system to control the dimming of the LED luminaries by using pulse width modulation (PWM).

The ILCS will create a safety and health condition in the workplace and also reduce energy consumption to avoid excessive illumination. Appropriate lighting should be maintained at all times through testing and regular maintenance. Under the Health and Safety at Work Act of 1974, an employer has a duty to ensure the health and safety of employees. The act includes a duty to provide lighting to ensure that work can be done safely and that employees health or 
eyesight are not jeopardized. Regulation no. 8 of the Workplace Regulations Act 1992 states that employers must ensure that:

(i) Every workplace has suitable and sufficient lighting.

(ii) This should be natural light, so far as is reasonably practicable.

Suitable and sufficient emergency lighting shall be provided where needed. In addition, ILCS also provides longer lamps' life that led to environment protection. This system is economically applicable where the visual task is relatively long for example in the classroom lighting and office lighting. The research focuses on an ergonomically design of the ILCS that can provide an appropriate lighting intensity, which eventually fight for the human being's visual requirement. For that reason, several objectives are to be met:

i. To design and build a prototype of energy saving smart LED lighting system with integrated sensors.

ii. To design a Graphical User Interface (GUI) using National Instrument LabVIEW software.

iii. To test the performance of the ILCS.

\section{MATERIALS AND METHOD}

ILCS comprises of three main modules that were uniquely integrated to represent the lighting intelligent system. This system capable of automatically controlled the intensity of illumination, which proportionately reduces consumption of energy.

\subsection{Sensor}

Basically, the system uses three types of sensors which are dynamically acting as input signals. These sensors provide different information which eventually being analyzed by the system to trigger further appropriate actions necessary based on presetting condition. First, the lux sensor or commonly known as photoresistor or light dependent resistor (LDR) whereas resistance decreases with increasing incident light intensity. This device also can be used to measure the amount of light level that falling on a surface of the device area in a unit of lux. Secondly, the motion sensor is used to sense human presence by detecting the change in incident infrared radiation and actuated by the difference in temperature between human body 
(which is a heat source) and floor, walls and other objects forming the background as shown in Fig. 1.

A third sensor is the PWM. PWM task is to control the amount of power going to the LED lamp. This is accomplished by generating a square wave. The duty cycle of the square wave is modulated by the output signal coming from the analog output module. LED lights must be driven with a constant current or voltage source. When reducing the forward current or voltage across an LED, it will dim slightly and then quickly drop off to zero light output. PWM can control the pulse width and duty cycle causing an LED light to vary its intensity as shown in Fig. 2. This works by turning the current off for an extremely short period of time, which eventually turned off the LED. The frequency could range from a hundred modulations per second to as high as hundreds of thousands of modulations per second; this makes the LED appear to be continuously lighted without any flickering. To produce an increased dimming effect, the LED will remain off for a longer period of time per duty cycle so the smaller the duty cycle the dimmer the light output. The eye will visually detect the LED as a continuous stream of light that only appears dimmer.

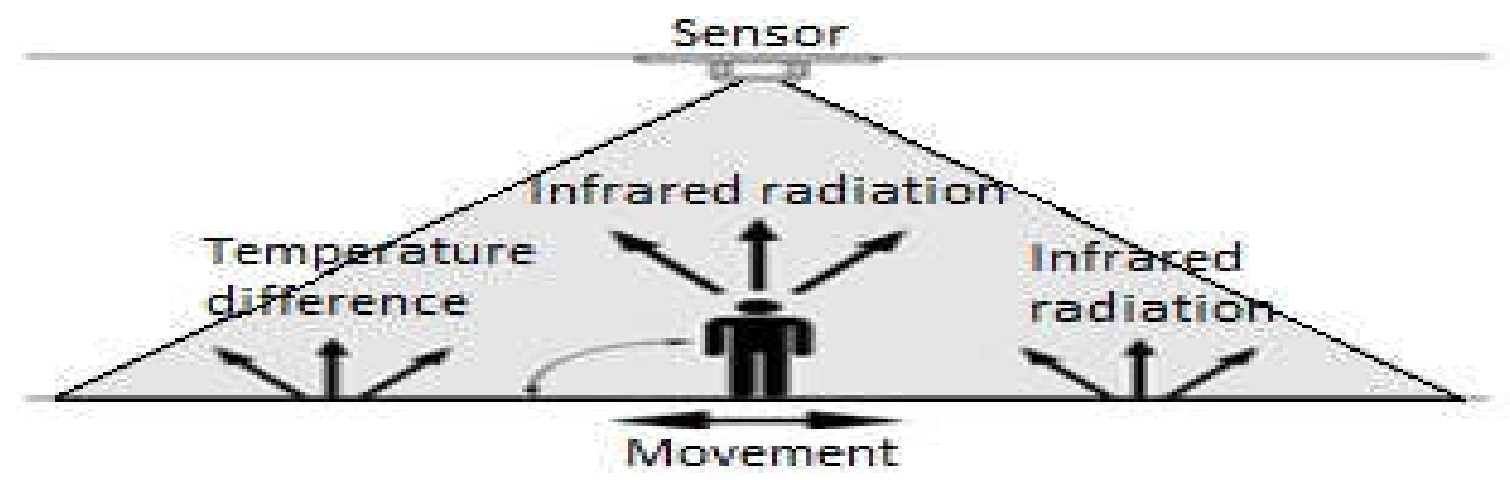

Fig.1. Motion sensor

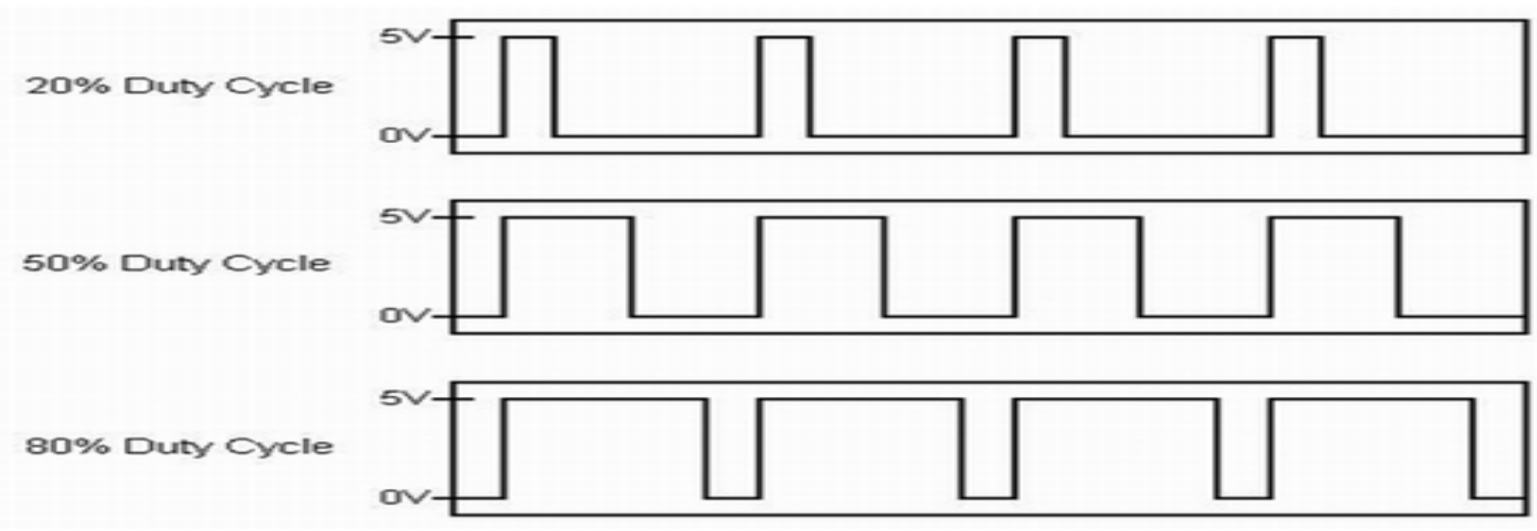

Fig.1. PWM signals with different duty cycles 


\subsection{Lighting System}

Measuring and maintaining the intensity of light is an imperative task because if the system could not supply adequate light would result in employee fatigue, muscle strain, and costly mistakes in work, particularly if an employee is exposed to insufficient lighting over long periods of time. The same is true for excessive light (or lux) levels. Glare and reflected light can distract an individual and impair his or her vision, which is particularly dangerous when a job requires the worker's full attention such as working with machinery or hazardous chemicals. Lux is a unit of illumination of one square meter, which is one meter away from a uniform light source. The amount of light (or lux) required to suit in the workplace depends on the type of work being done. Table 1 gives an indication of the light (or lux levels) required for different types of working environments. The extent to which good quality lighting enhances work performance depends on the visual component of the task. A task with an important visual component will benefit more from good seeing conditions than a task with a less important visual component. Table 2 summarizes that increase in task performance and reduction in the number of rejects as a result of improvements in lighting level [21].

Table 1. Lux level and environmental requirement

\begin{tabular}{cc}
\hline Environment & Required Light Level \\
\hline Storage area/plant room (minimal movement) & $150-200$ Lux \\
Construction area and loading bays (minimal movement) & $300-500$ Lux \\
Factories and kitchen (higher perception of detail) & $500-750$ Lux \\
Inspection welding and machinery (demanding work) & 750-1000 Lux \\
Electronics and textile production (repetitive work) & 1000-1500 Lux \\
Technical offices (accurate detail) & $1500-3000$ Lux \\
Jewelers and goldsmith (precision detail) & $3000+$ Lux \\
\hline
\end{tabular}


Table 2. Lighting level and task performance

\begin{tabular}{|c|c|c|c|c|}
\hline \multirow[t]{2}{*}{ Type of Work } & \multicolumn{2}{|c|}{ Lighting Level (Lux) } & \multirow{2}{*}{$\begin{array}{c}\text { Increase in Task } \\
\text { Performance } \\
(\%)\end{array}$} & \multirow{2}{*}{$\begin{array}{l}\text { Reduction in } \\
\text { Number of } \\
\text { Rejects (\%) }\end{array}$} \\
\hline & Before & After & & \\
\hline Camera assembly & 370 & 1000 & 7 & - \\
\hline Leather punching & 350 & 1000 & 8 & - \\
\hline Composing room & 100 & 1000 & 30 & 18 \\
\hline Fine assembly work & 500 & 1500 & 28 & - \\
\hline Metal Industry & 300 & 2000 & 16 & 29 \\
\hline $\begin{array}{l}\text { Difficult visual task in the } \\
\text { metal industry }\end{array}$ & 500 & $1600-2500$ & 10 & 20 \\
\hline Miniature assembly & $500-1000$ & 4000 & - & 90 \\
\hline Weaving mill & 250 & 1000 & 7 & - \\
\hline
\end{tabular}

\subsection{Graphical User Interface}

The design of the GUI using LabView allows users to interact with electronic devices using graphic icons rather than text commands. LabVIEW is a programming environment that features a data flow-based Virtual Programming Language VPL (called G) designed to facilitate development of data acquisition, analysis, display and control applications [22-28]. The program developed by National Instruments is widely used in the industry for a variety of applications. One of these important applications is the automation of information gathering. Since many experiments are done under controlled conditions, changing these controlling conditions becomes a major part of this research.

\section{RESULTS AND DISCUSSION}

\subsection{Hardware Development}

The system can be explicitly divided into two parts. The first part deals with hardware development which involved the connection of light sensors, motion sensor and LED lamp to host computer via LabVIEW Data Acquisition. The second part deals with the software development which involved programming of LabVIEW for GUI window to control the luminosity of light through PID controller. Both parts are integrated in such away in order to provide a real time control of the intensity of illumination. The Passive Infra-Red (PIR) motion sensors are placed near the LED lamp will detect the movement or presence of 
humans. When the human passing through the cover area, the motion sensor will transmit the signal as an input to the CompactRIO Real Time Data Acquisition. The signal from the PIR motion sensor will trigger the system to get ready to control the illumination of LED light base for ergonomic setting. The light sensor that is placed under the LED lamp will measure the light level in lux unit. The measured light level will then be compared to a desired luminous setting using PID controller. The host computer will display the current luminous of LED lamp and the other information through the GUI, which was designed with LabVIEW environment. Fig. 3 shows the block diagram of an ILCS.

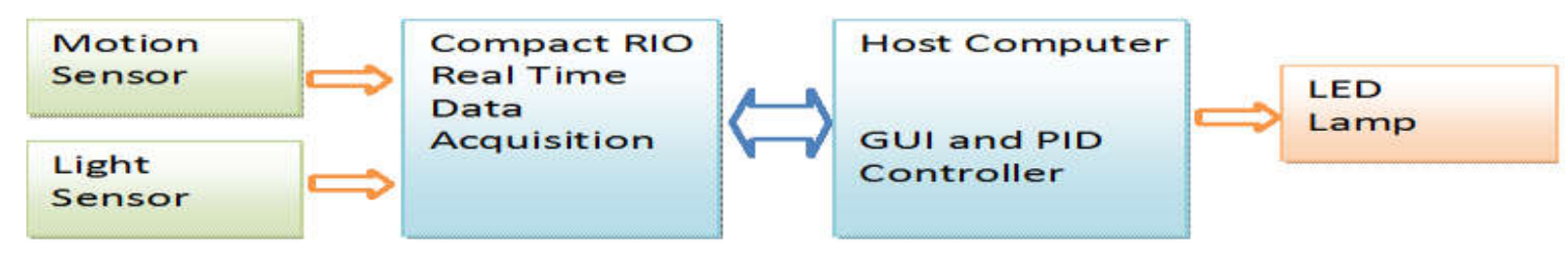

Fig.2. Block diagram of ILCS

\subsection{Software Development}

When the hardware circuit is determined, the system software is programmed using NI LabVIEWthat used to create a GUI in this research project. The overview of the software component modules as shown in figure 4, which displays the important information that needs to analyze the prototype of the ILCS. The main important information is to obtain the PID graph which will display the ability of the PID system to control the LED lamp. To show the system developed can achieve the objective of the project, the graph will display the stability the luminous of LED lamp in the lux unit in a real time performance based on the desired luminous set point. Other information which will be used to analyze the system such as luminous, intensity, current and the voltage of the LED lamp will also be displayed. 


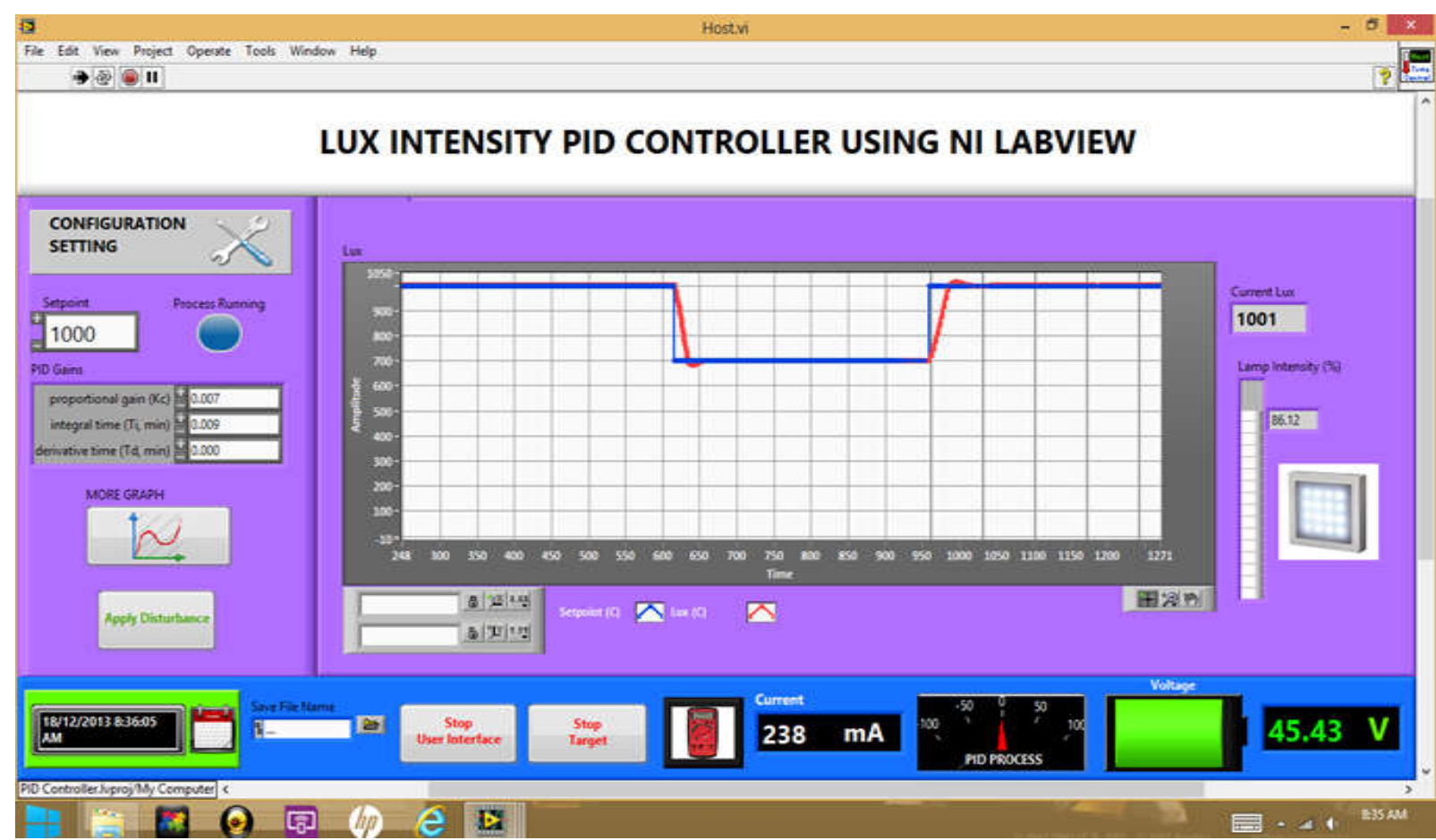

Fig.3. Main GUI for ILCS

The software and hardware developed were then physically integrated to form one complete prototype of the ILCS system as shown in Fig. 5 and Fig. 6. The schematic model diagram of the hardware and the software illustrating the interconnectivity of the system designed is shown in Fig. 7. 


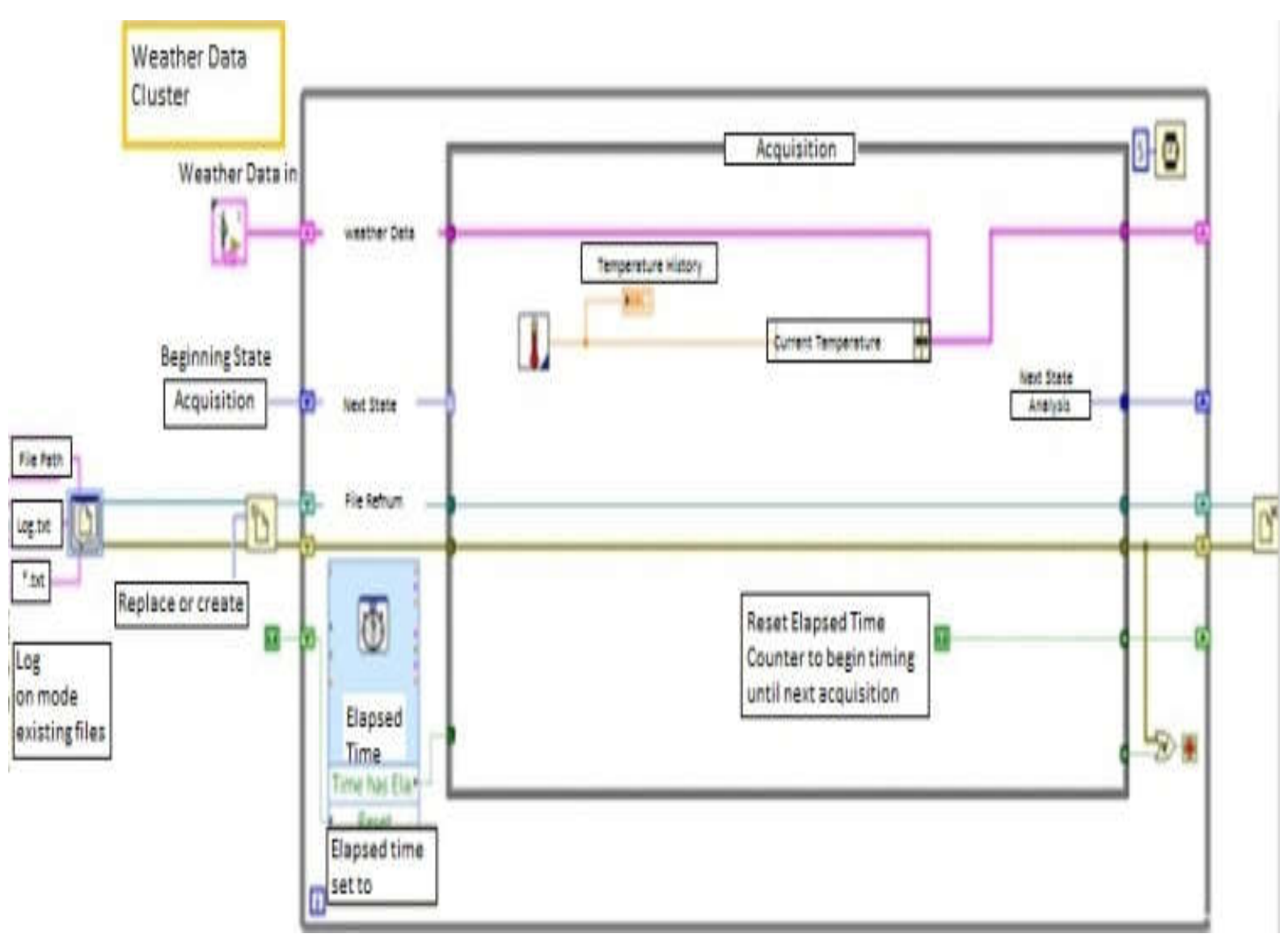

Fig.5. Design and modelling of ILCS component modules in LabVIEW environment

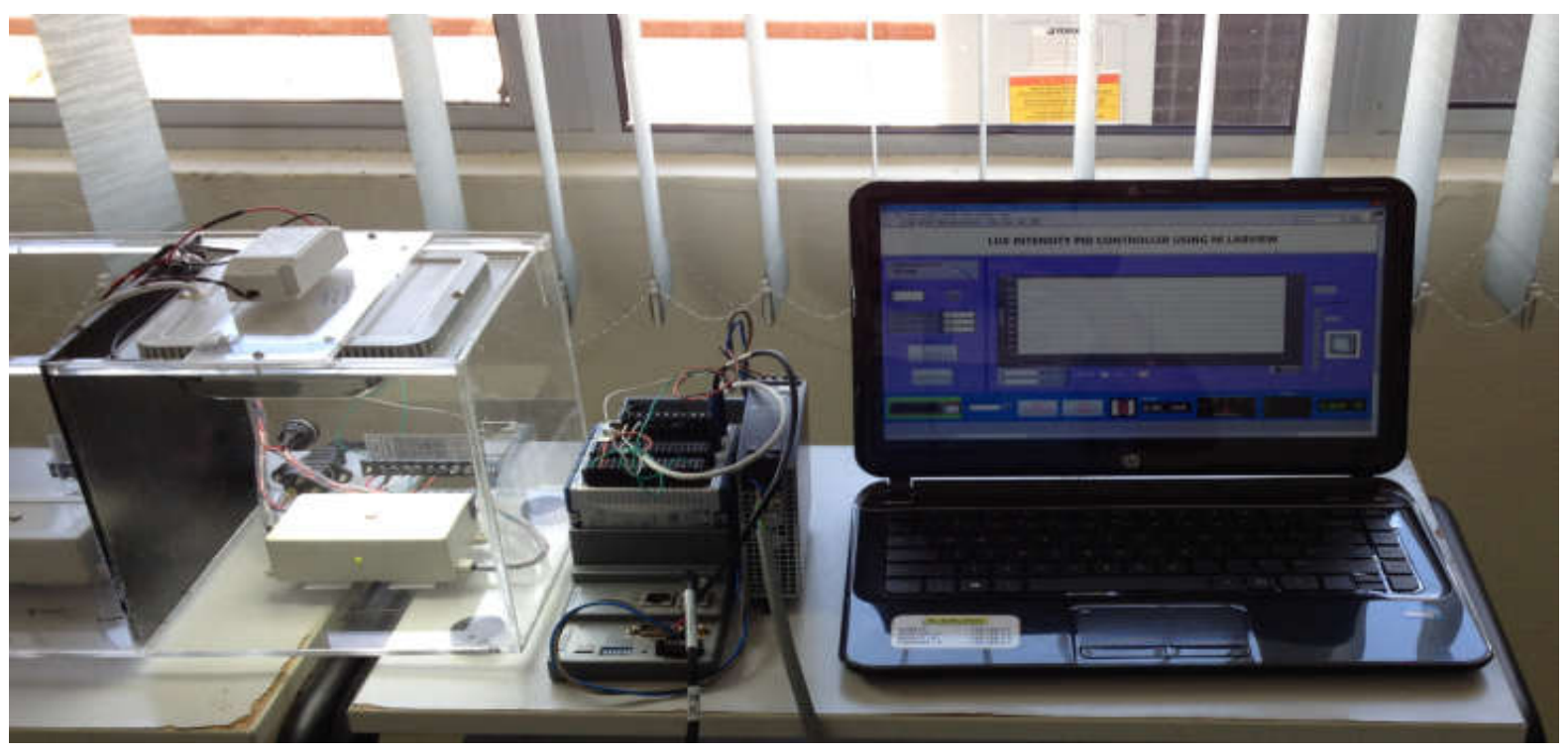

Fig.6. Prototype of ILCS 


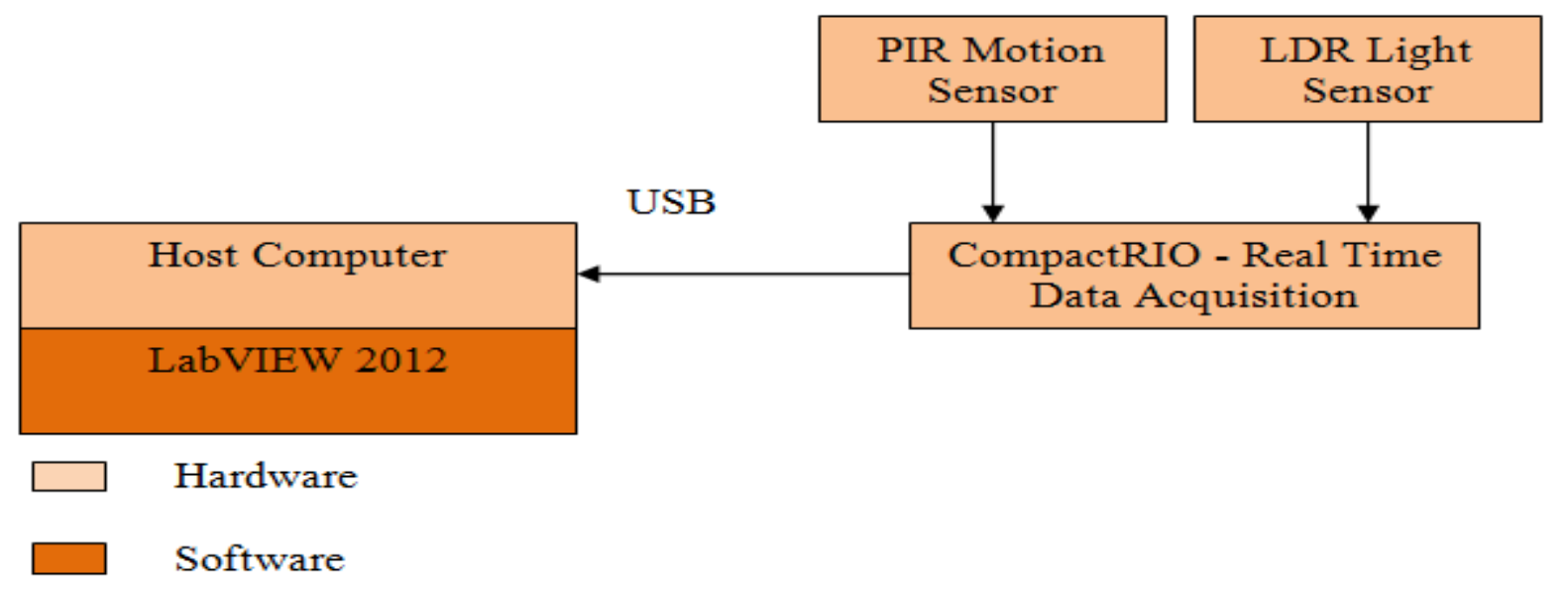

Fig.7. Block diagram integration of ILCS

\section{CONCLUSION}

Prototype of the ILCS has been developed using the NI CompactRIO as a main embedded hardware. The test conducted 4 hour of running time showed that the ILCS creates a safety and health condition in the workplace to avoid excessive illumination, as well as provided an average power saving of up to $33 \%$ as illustrated in Fig. 8 .

\section{Result of the Power Consumption (8pm-12pm)}

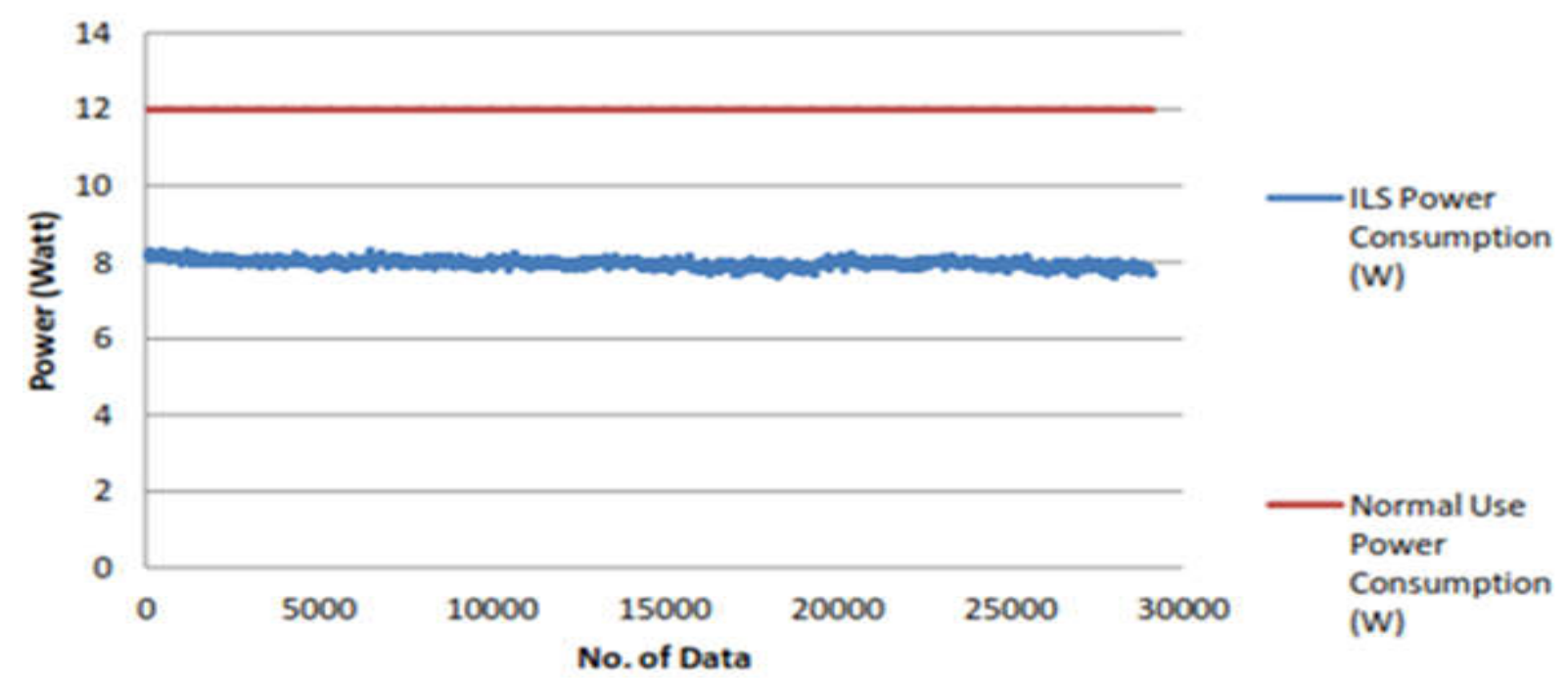

\begin{tabular}{|c|c|c|c|c|}
\hline $\begin{array}{c}\text { Average Light } \\
\text { Intensity } \\
\text { I\% }\end{array}$ & $\begin{array}{c}\text { Average } \\
\text { Voltage } \\
\text { Nolt }\end{array}$ & $\begin{array}{c}\text { Average Current } \\
\text { / mA }\end{array}$ & $\begin{array}{c}\text { Average Power } \\
\text { / Watt }\end{array}$ & $\begin{array}{c}\text { Average Power } \\
\text { Saving/\% }\end{array}$ \\
\hline 81.32 & 39.68 & 201.11 & 7.98 & 33.05 \\
\hline
\end{tabular}

Fig.8. Result of power consumption 
However, several other improvements are recommended in order to further improve the system accuracy and efficiency.

- Use high precision and sensitive of a digital light sensor such as TSL2561 instead of using analog LDR sensors which can sense and reading light level more accuracy. The TSL2561 luminosity sensor is an advanced digital light sensor, which ideal for use in a wide range of light situations.

- Install the ILCS system in the classroom or other compartment to replace the existing lighting to obtain more accuracy validation data in actual condition.

- Replace the NI CompactRIO hardware with NI MyRIO hardware, which can minimize the hardware cost without losing the efficiency of the hardware.

\section{ACKNOWLEDGEMENTS}

The author's sincerely thank the Faculty of Manufacturing Engineering, Universiti Teknikal Melaka (UTeM), Malaysia and East Coast Environmental Research Institute (ESERI), Universiti Sultan Zainal Abidin (UniSZA) for the help and financial support given.

\section{REFERENCES}

[1] Mohamed S B, Jameel A, Minhat M. A review on intelligence STEP-NC data model and function blocks CNC machining protocol. Advanced Materials Research, 2014, 845:779-785

[2] Miki M, Nagano M, Yoshimi M, Yonemoto H, Yoshida K. Intelligent lighting system with an additional energy-saving mechanism. In IEEE International Conference on Systems, Man, and Cybernetics, 2012, pp. 3173-3178

[3] Lin Y, Cheng W, Wu C, Sun Y. An intelligent lighting control system based on ergonomic research. In International Conference on Consumer Electronics, Communications and Networks, 2011, pp. 4744-4747

[4] Wang H, Pandharipande A, Caicedo D. Distributed lighting control of locally intelligent luminaire systems. In IEEE International Conference on Systems, Man, and Cybernetics, 2012, pp. 3167-3172

[5] Fischer M, Wu K, Agathoklis P. Intelligent illumination model-based lighting control. In 32nd International Conference on Distributed Computing Systems Workshops, 2012, pp. 245-249 
[6] Byun J, Hong I, Lee B, Park S. Intelligent household LED lighting system considering energy efficiency and user satisfaction. IEEE Transaction on Consumer Electronic, 2013, 59(1):70-76

[7] Hamed B. Design and implementation of smart house control using LabVIEW. International Journal of Soft Computing and Engineering, 2012, 1(6):98-106

[8] Bangali J, Shaligram A. Energy efficient smart home based on wireless sensor network using Labview. American Journal of Engineering Research, 2013, 2(12):409-413

[9] Bhatt J G, Verma H K. RS-485/MODBUS based intelligent building automation system using LabVIEW. In 4th International Conference on Computer Applications in Electrical Engineering-Recent Advances, 2010, pp. 19-21

[10] Chiogna M, Mahdavi A, Albatici R, Frattari A. Energy efficiency of alternative lighting control systems. Lighting Research and Technology, 2012, 44(4):397-415

[11] Wang Y, Wang Z. Design of intelligent residential lighting control system based on Zigbee wireless sensor network and fuzzy controller. In International Conference on Machine Vision and Human-Machine Interface, 2010, pp. 561-564

[12] Baig F, Mahmood A, Javaid N, Razzaq S, Khan B, Saleem Z. Smart home energy management system for monitoring and scheduling of home appliances using Zigbee. Journal of Basic and Applied Scientific Research, 2013, 3(5):880-891

[13] Jin M L, Ho M C. Labview-based fuzzy controller design of a lighting control system. Journal of Marine Science and Technology, 2009, 17(2):116-121

[14] Chang S, Mahdavi A. A hybrid system for daylight responsive lighting control. Journal of the Illuminating Engineering Society, 2002, 31(1):147-157

[15] Tse W L, Chan W L, Lai S S. Emergency lighting monitoring system using LonWorks. Automation in Construction, 2003, 12(5):617-629

[16] Panjaitan S D, Hartoyo A A lighting control system in buildings based on fuzzy logic. TELKOMNIKA (Telecommunication Computing Electronics and Control), 2013, 9(3):423-432

[17] Saravanan R. Fuzzy controller design of lighting control system by using VI package. IAES International Journal of Artificial Intelligence, 2012, 1(2):73-78

[18] Huang C H, Su Y F, Su Y T, Su W H, Chen J J, Zhou W J. Design and application of ZigBee wireless techniques for an intelligent house lighting control system. In International Symposium on Computer, Consumer and Control, 2014, pp. 19-22 
[19] Andrei H, Cepisca C, Dogaru-Ulieru V, Ivanovici T, Stancu L, Andrei P C. Measurement analysis of an advanced control system for reducing the energy consumption of public street lighting systems. In IEEE Bucharest PowerTech, 2009, pp. 1-6

[20] Wang S C, Liu Y H. High-power-factor electronic ballast with intelligent energy-saving control for ultraviolet drinking-water treatment systems. IEEE Transactions on Industrial Electronics, 2008, 55(1):142-153

[21] Van Bommel I W, Van den Beld I G, Van Ooyen I M. Industrial lighting and productivity. Eindhoven: Philips Lighting, 2002

[22] Whitley K N, Blackwell A F. Visual programming in the wild: A survey of LabVIEW programmers. Journal of Visual Languages and Computing, 2001, 12(4):435-472

[23] Wang H, Pandharipande A, Caicedo D, Van Den Bosch P P. Distributed lighting control of locally intelligent luminaire systems. In IEEE International Conference on Systems, Man, and Cybernetics, 2012, pp. 3167-3172

[24] $\mathrm{Xu} \mathrm{K}$. The design concept of a virtual experiment teaching platform for digital logic based on LabVIEW. International Journal of Hybrid Information Technology, 2015, $8(2): 229-236$

[25] Reddy B N, Suresh N, Ramesh J V, Pavithra T, Bahulya Y K, Edavoor P J, Ram S J. An efficient approach for design and testing of FPGA programming using Lab VIEW. In IEEE International Conference on Advances in Computing, Communications and Informatics, 2015, pp. 543-548

[26] Wang H Y, Liu M Z, Chen Z M, Qiao J J. Design on virtual experiment system for communication principle based on LabVIEW. In D. Wang (Ed.), Electronic Engineering and Information Science: Proceedings of the International Conference of Electronic Engineering and Information Science 2015 (ICEEIS 2015). Florida: CRC Press, 2015

[27] Ismail W O, Hanif M, Mohamed S B, Hamzah N, Rizman Z I. Human emotion detection via brain waves study by using electroencephalogram (EEG). International Journal on Advanced Science, Engineering and Information Technology, 2016, 6(6):1005-1011

[28] Minhat M, Mohamed S B, Kasim M S, Sulaiman M A, Rizman Z I. Advanced manufacturing of an aircraft component (fish-head): A technology review on the fabrication. International Journal on Advanced Science, Engineering and Information Technology, 2016, 6(5):734-739.

\section{How to cite this article:}

Mohamed SB, Minhat M, Kasim MS, Adam MHM, Sulaiman MA, Rizman ZI.An intelligent lighting control system (ilcs) using labview. J. Fundam. Appl. Sci., 2017, 9(2S), 602-615. 